\title{
EGU2020-14021
}

https://doi.org/10.5194/egusphere-egu2020-14021

EGU General Assembly 2020

(c) Author(s) 2021. This work is distributed under

the Creative Commons Attribution 4.0 License.

\section{Vesta Project - Enhancement and safeguarding of cultural heritage through innovative technologies}

\author{
Francesco Soldovieri ${ }^{1}$, Nicole Dore ${ }^{2}$, Valerio Corini ${ }^{2}$, Ilaria Catapano ${ }^{1}$, Rosa Lasaponara ${ }^{1}$, Enzo \\ Rizzo ${ }^{1}$, Federico Saccoccio ${ }^{3}$, Francesca Cocco ${ }^{4}$, and Annamaria Capodanno ${ }^{4}$

The VESTA project (Valorizzazione E Salvaguardia del paTrimonio culturAle attraverso l'utilizzo di tecnologie) deals with the experimental integration of advanced technologies designed for safeguarding and prospecting sub-soil and ancient structures as well as the management of the information derived from the carried out investigations. The final goal is to support the end users with regard to their conservation, safeguard and discovery activities.

The pilot site test of the Project is the Archaeological Park of Paestum, which is located in the Southeast of the Gulf of Salerno, Italy, and was built by the Greeks and later strengthened by the Lucani and the Romans. Today, the Archaeological Park of Paestum is recognised by UNESCO as part of the World Cultural Heritage thanks to the excellent state of conservation of its structures, especially the three majestic temples: the Temple of Hera (sixth century BC), the Temple of Neptune (fifth century BC) and the Temple of Ceres (sixth century BC). These are remarkable examples of Doric style architecture.

The technological skills made available by the VESTA team are based on:

- Earth observation tools, such as satellites (optical and radar) for the large-scale identification of critical issues, both natural and anthropic, involving cultural heritage and around them;

- Mini-micro UAV (Unmanned Aerial Vehicle) equipped with multispectral, thermal and radar optical sensors and aimed at detailed soil and wall structure analysis;

- High and low frequency terrestrial radar (GPR - Ground Penetrating Radar) for inspections of masonry and subsoil structures respectively;

- Electrical Resistivity Tomography (ERT) for the investigation of the subsoil.

These technological solutions are key tools for identifying and mapping possible degradation phenomena of ancient structures identifying dangers related to the surrounding environment that could compromise the state of conservation of the monuments inside the park. Therefore, their use as well as the cooperative exploitation of the provided results allow an improvement of 
knowledge about the critical aspects of the territory and the state of conservation of the artefacts, in order to facilitate the planning of maintenance interventions. Specifically, the gathered data are made available to site manager via St'ART ${ }^{\mathrm{T} M}$ web platform, which allows a simple consultation of results collected during VESTA project campaigns thanks to reports and thematic maps.

Acknowledgment: The authors would like to thank the VESTA project "Valorizzazione E Salvaguardia del paTrimonio culturAle attraverso I'utilizzo di tecnologie innovative" by which the present work has been financed. The VESTA project is co-founded by the Campania Region within the POR-FESR 2014-2020 program. 